Topics

\title{
Opening of the New Japanese Balloon Base at the Taiki Aerospace Research Field
}

\author{
By Hideyuki FuKe, Daisuke AKITA, Issei IIJIMA, Naoki IzUTSU, Yoichi KATO, Jiro KaWADA, \\ Yukihiko MatsuZaKa, Eiichi Mizuta, Michiyoshi NAMIKI, Naoki NonAKA, Shigeo OHTA, \\ Yoshitaka SAIto, Takatoshi SAto, Motoharu SEO, Atsushi TAKADA, Keisuke TAMURA, \\ Michihiko TORIUMI, Kazuhiko YAMADA and Tetsuya YosHIDA
}

Institute of Space and Astronautical Science, Japan Aerospace Exploration Agency (ISAS/JAXA), Sagamihara, Japan

\author{
(Received July 16th, 2009)
}

\begin{abstract}
The Japanese balloon base was moved from the Sanriku Balloon Center (SBC) to the Taiki Aerospace Research Field (TARF). The SBC was closed in September 2007, and the new base at the TARF became operational in May 2008. In 2008, the first series of balloon flights at the TARF was carried out. By the success of these flights, we verified that the whole system of the new balloon base is well established. From FY 2009, regular balloon operations with science payloads started at the TARF. In May/June 2009, flight operations of three science experiments were carried out successfully. Five more science flights are planned at the TARF in August/September 2009.
\end{abstract}

Key Words: Stratospheric Balloon, Balloon Base, New Facilities, Flight Operation

\section{Introduction}

The Japanese balloon base was moved from the Sanriku Balloon Center (SBC) to the Taiki Aerospace Research Field (TARF) in Taiki, Hokkaido (Fig. 1). The facilities for the new balloon base were constructed at the TARF during July 2007 and March 2008. The SBC was closed in September 2007, and equipment was transferred from the SBC to the TARF. The new base at the TARF is designed to launch larger balloons with greater safety and to perform balloon operations more effectively than at the SBC.

Details of the new balloon facilities including the sliding launcher, the balloon operation building, and meteorological equipment, as well as details of the updated semi-dynamic launching method realised by the sliding launcher and a huge hangar, are described in Ref. 1.

The flight window at the TARF is expected to be available in the same season as that at the SBC: from mid-May to

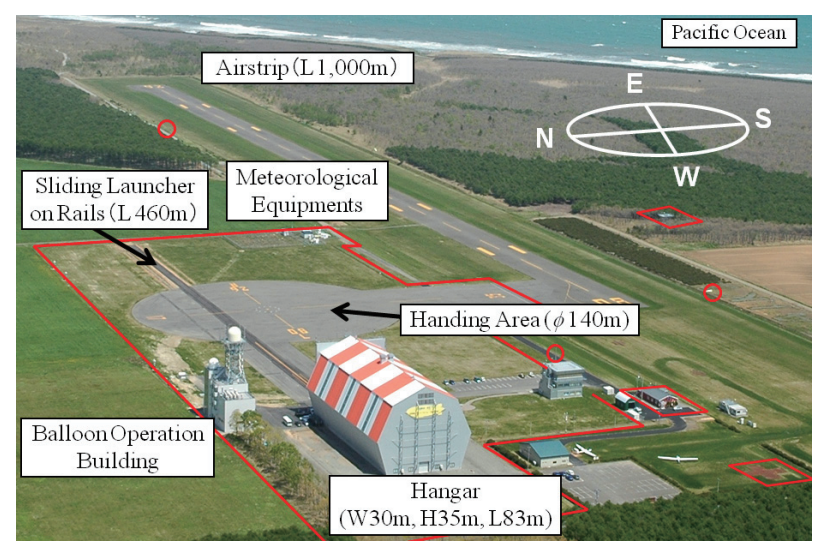

Fig. 1. A bird's-eye view of the Taiki Aerospace Research Field (TARF). The area of the TARF is shown by red lines.
mid-June and from mid-August to mid-September. As for the recovery, the payload and the balloon are planned to be recovered on the sea, as was done at the $\mathrm{SBC}$, for the time being.

The new balloon base at the TARF became operational in May 2008. In FY 2008, the first series of engineering balloon flights at the TARF was planned in order to verify the performance of the new balloon base operation system. Subsequently, in FY 2009, the first series of regular balloon operations with science payloads at the TARF was planned. The accumulation of these balloon operations has been expected to prove the advantages of the new balloon base which can open a "new era" of the scientific balloon in Japan.

In this paper, we describe the detailed plans and results of balloon operations, which were carried out in FY 2008 and are in progress in FY 2009.

\section{First Series of Balloon Flights at the TARF}

In May 2008, prior to the real balloon flight, several tests were carried out to verify the basic performance of each operation system. The performance of the sliding launcher and the procedure of the updated semi-dynamic launching method were verified through a series of tests using a reusable urethane balloon anchored to the ground. The track-telemetryand-command system was checked not only by ground tests but also by flights of small path-finder balloons. By these tests, the operation of every system was confirmed to work well.

Based on the success of these tests, two flights of heavy stratospheric balloons were planned. These first two balloon flights from the TARF were positioned as engineering flights to verify the whole operation procedure including the launch, the track-telemetry-and-commanding, and the recovery. Mock-up payloads with dummy weights inside were prepared.

On $23^{\text {rd }}$ August 2008, the first engineering flight attempt,

Copyright $\bigodot 2010$ by the Japan Society for Aeronautical and Space Sciences and ISTS. All rights reserved. 
"B08-01", was carried out. The $100,000 \mathrm{~m}^{3}$ balloon with a total lift of 1.0 tonne was successfully launched and reached the level altitude of $33.5 \mathrm{~km}$. After floating for an hour and a half, the payload was separated from the balloon and recovered on the sea. The altitude profile during the flight is shown in Figure 2.

The aim of the second engineering flight, "B08-02", was to verify the whole balloon operation with a larger balloon, a bigger payload, a larger lift, and higher altitudes. The B08-02 balloon with a volume of $300,000 \mathrm{~m}^{3}$ and a total lift of 1.2 tonne was launched on $5^{\text {th }}$ September 2008 (Fig. 3). After reaching the level altitude of $41.2 \mathrm{~km}$, the balloon and the payload were separated and successfully recovered on the sea by chartered fishing boats and coastal ships (Fig. 4).

Table 1 summarises the specifications of B08-01 and B08-02.

With the success of the first series of stratospheric balloon flights from the TARF, we verified that the whole system of the new balloon base is well established.

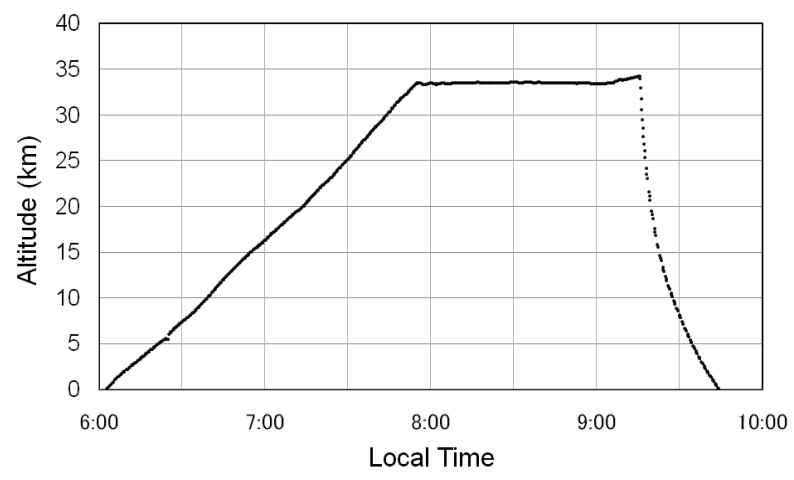

Fig. 2. Altitude profile (GPS data) of B08-01.

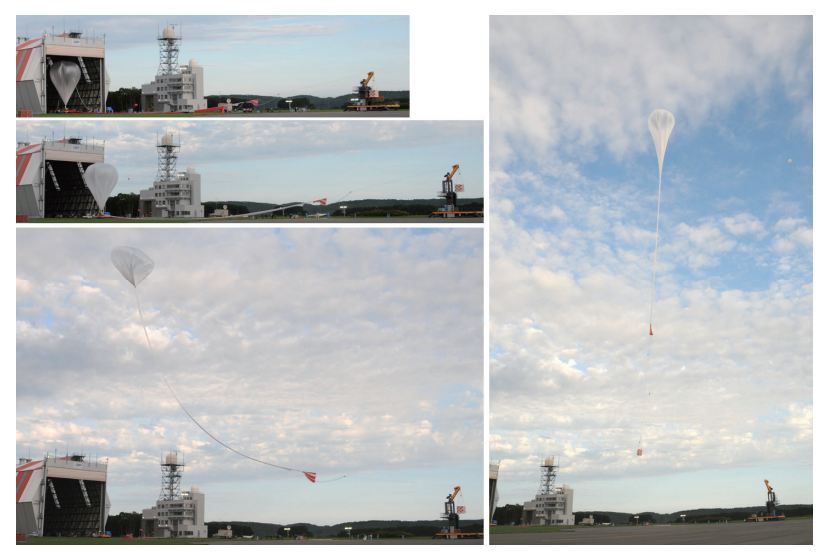

Fig. 3. Sequential photographs of the launch of B08-02 using the sliding launcher. Once the balloon was inflated inside the hangar, the whole flight train was moved to outside the hangar. Then, the balloon was released from the leap-up-type launch spool. The turntable of the launch platform was rotated to match the surface wind direction, and the airbag-type collar was released. Then, the flight train rose into the sky.
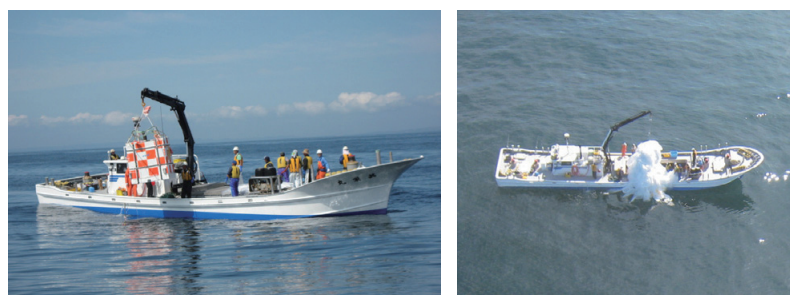

Fig. 4. Recovery of the payload (left figure) and the balloon (right figure) of B08-02 on the sea.

Table 1. Specifications of B08-01 and B08-02.

\begin{tabular}{|l|c|c|}
\hline Balloon ID & B08-01 & B08-02 \\
\hline Balloon volume & $100,000 \mathrm{~m}^{3}$ & $300,000 \mathrm{~m}^{3}$ \\
\hline Total lift & 1.0 tonne & 1.2 tonne \\
\hline Total weight & 0.95 tonne & 1.1 tonne \\
\hline Payload weight (without ballast) & $372 \mathrm{~kg}$ & $219 \mathrm{~kg}$ \\
\hline Payload dimensions & $1.5 \mathrm{~m}^{\mathrm{W}}, 1.5 \mathrm{~m}^{\mathrm{L}}, 1.5 \mathrm{~m}^{\mathrm{H}}$ & $6.0 \mathrm{~m}^{\mathrm{W}}, 1.5 \mathrm{~m}^{\mathrm{L}}, 1.5 \mathrm{~m}^{\mathrm{H}}$ \\
\hline Launch date & $23^{\text {rd }} A u g .2008$ & $5^{\text {th }} S e p .2008$ \\
\hline Reached level altitude & $33.5 \mathrm{~km}$ & $41.2 \mathrm{~km}$ \\
\hline
\end{tabular}

\section{First Series of Science Flights at the TARF}

\subsection{Science flights planned in 2009}

Based on the success of the verification of the entire balloon-base system in 2008, from FY2009 balloon operations with science payload are begun at the TARF.

As the first series of "science flights" at the TARF, eight balloon flights are planned in 2009 (Table 2). The subjects of the science flights are selected annually from among applicants by the ISAS/JAXA Scientific Balloon Program Advisory Committee.

The eight experiments originate from various fields such as: astronomy (B09-02), astrophysics (B09-08), planetary science (B09-03), geoenvironmental science (B09-05), space environment utilisation (B09-01), space technology (B09-04 and 06), and the next-generation balloon development (B09-07).

Table 2. Science flights planned in 2009 .

\begin{tabular}{|c|l|c|c|}
\hline ID & \multicolumn{1}{|c|}{ Objects } & Ref. & When \\
\hline B09-01 & Micro-gravity experiment. & 2) & May-Jun. \\
\hline B09-02 & Polarisation observation of astronomical X-ray. & 3) & May-Jun. \\
\hline B09-03 & Observation of Venus atmosphere. & 4) & May-Jun. \\
\hline B09-04 & Test of flexible aeroshell re-entry system. & 5) & Aug.-Sep. \\
\hline B09-05 & Cryogenic sampling of stratospheric air. & 6) & Aug.-Sep. \\
\hline B09-06 & Test of solar sail deployment. & 7) & Aug.-Sep. \\
\hline B09-07 & Test of super-pressure balloon. & 8) & Aug.-Sep. \\
\hline B09-08 & Cosmic-ray electron and gamma-ray observation. & 9),10) & Aug.-Sep. \\
\hline
\end{tabular}

\subsection{First science flight at the TARF}

The first science flight at the TARF, B09-01, was carried out on $27^{\text {th }}$ May 2009.

B09-01 is a free-fall micro-gravity experiment ${ }^{2)}$ with two payloads: a rocket-shaped $4 \mathrm{~m}$-long capsule which has a double-shell drag-free structure, and a control gondola which has bus equipment for the balloon operation. The capsule is hanged beneath the control gondola and is released from the control gondola at the high balloon altitude. During the 
free-fall, the capsule provides a high-quality micro-gravity environment to its inner shell experiment-module.

The B09-01 balloon with a volume of $300,000 \mathrm{~m}^{3}$ was successfully launched on the morning of $27^{\text {th }}$ May. The balloon reached to the level altitude of $40.0 \mathrm{~km}$, and the capsule was released. During the descent, the capsule realised a micro-gravity environment for around 35 seconds as planned. The quality of the achieved micro-gravity environment (around $10^{-4} \mathrm{G}$ at $10 \mathrm{~Hz}$ ) was comparable to (or even better than) that at the International Space Station.

The capsule was safely splashed down on the sea by using a two-stage supersonic parachute system. The parachute system consists of a hemisflo-type drogue parachute with a riblessguide-surface-type pilot-chute, and a flat-type main parachute.

After the release of the capsule, the control gondola was separated from the balloon. Both of the control gondola and the balloon were also successfully recovered on the sea. For the recovery of B09-01, three boats and one ship were chartered.

The capsule was recovered by a helicopter on the sea and was brought to the TARF. This was the first helicopter recovery at the TARF (Fig. 5).

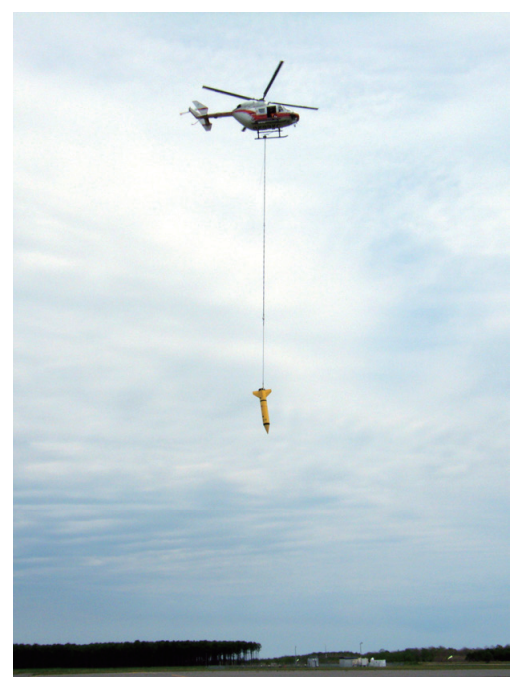

Fig. 5. The B09-01 capsule recovered by a helicopter.

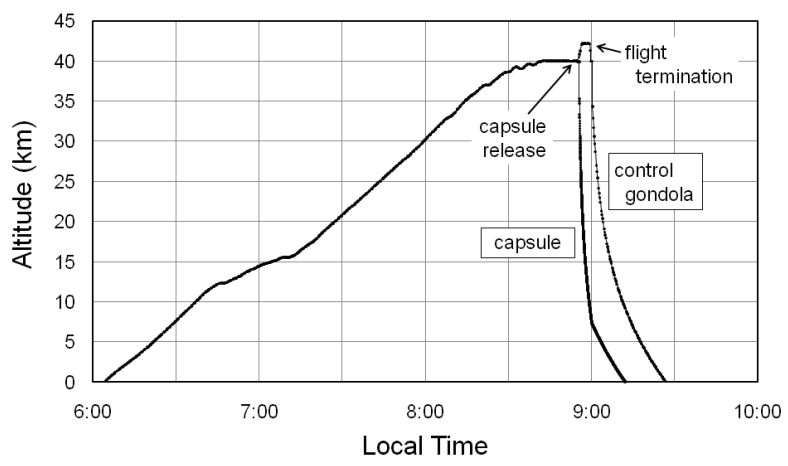

Fig. 6. Altitude profiles (GPS data) of two B09-01 payloads.
The three bodies which descended separately (i.e. the capsule, the control gondola, and the balloon) were each tracked independently by three telemetry antennas set at the TARF: two antennas ${ }^{1)}$ on the rooftop of the balloon operation building, and a stand-alone mobile station named LASCOS, Low Altitude Space Communication System ${ }^{11)}$, set besides the balloon operation building. Figure 6 shows the altitude profiles of two payloads (the capsule and the control gondola) during the flight. The detailed analysis of the flight data is in progress.

\subsection{First boomerang flight at the TARF}

The second science flight at the TARF, B09-03, was carried out on $3^{\text {rd }}$ June. B09-03 is a prototype flight of a telescope for the Venus atmosphere observation ${ }^{4}$.

In order to get enough float time in keeping the policy of recovery on the coast near the launch site, we carried out the "boomerang flight" 12). The ascending of the balloon (volume $100,000 \mathrm{~m}^{3}$ ) was once stopped by removing the free lift, and the balloon was flown eastward by the strong jet stream. The balloon ascent was resumed by dropping the ballast, and the balloon came back westward at the float altitude.

The boomerang flight operation has been developed to elongate the flight time with a safe recovery in the limited national territory of Japan. The seasonal wind pattern above Japan shows that we can expect both of moderate east wind in

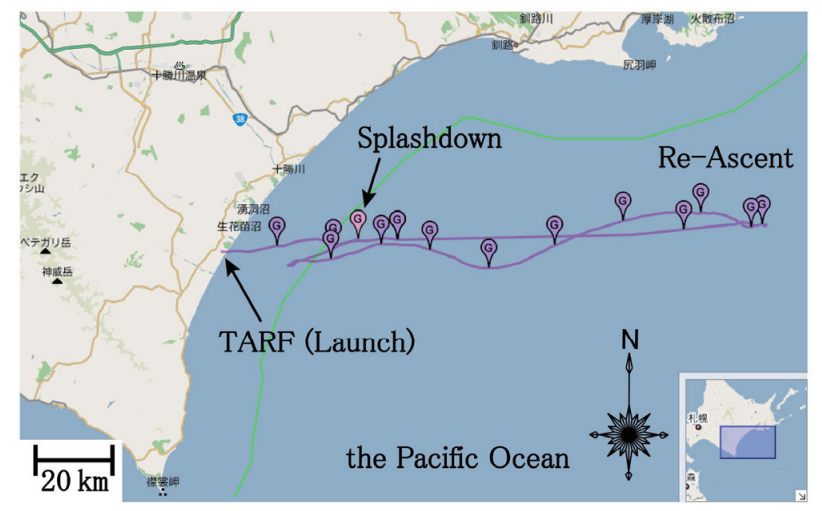

Fig. 7. Flight trajectory of the B09-03 boomerang flight. (Copyright of the map data: Google and ZENRIN).

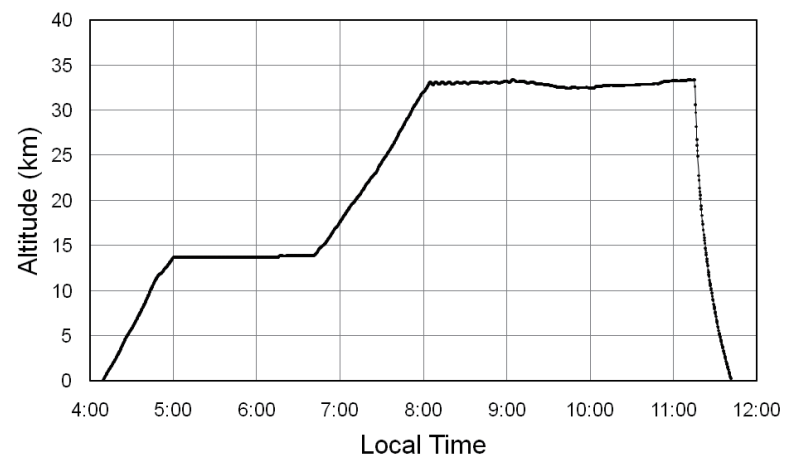

Fig. 8. Altitude profile (GPS data) of the B09-03 boomerang flight. 
the upper stratosphere and the strong west-wind jet stream during mid-May to mid-June and during mid-August to mid-September. This is a major reason why the flight window is set in these periods. We plan to utilise the boomerang flight operation at the TARF, as was done at the SBC.

B09-03 was the first boomerang flight at the TARF. The flight trajectory and the altitude profile of B09-03 are shown in Figures 7 and 8. By the success of this flight, it was verified that the boomerang flight operation can be utilised at the TARF.

\subsection{Third science flight with larger lift and longer flight}

The third science flight, B09-02, was performed on $18^{\text {th }}$ June. B09-02 is an experiment of a polarimeter to observe astronomical X-rays ${ }^{3)}$.

The initial lift in the $300,000 \mathrm{~m}^{3}$ balloon was 1.64 tonne, and the total flight train length was about $190 \mathrm{~m}$. These numbers are maximum records at the TARF at present. At the SBC, it was difficult to launch such a large flight-train-system in the limited launch pad (160 m long).

The B09-02 flight was a long boomerang flight. The flight time between the launch and the splash down (11.2 hours) and the maximum slant range from the TARF during the flight (about $320 \mathrm{~km}$ ) are also maximum records at the TARF at present.

Until the launch day, B09-02 was not blessed with good weather. For the balloon flight, all the weather requirements should be met; the weather on the ground should be without rain with calm or light wind, the upper wind should be suitable for the flight (in this case for the boomerang operation), and the sea condition should be suitable for the sea recovery.

In order not to miss the flight opportunity, the B09-02 payload had to wait for 9 days being ready for the launch. Thanks to the large hanger and the sliding launcher at the TARF, the payload could wait for these 9 days on the launcher indoors. This was not possible at the SBC.

The implementation of B09-02 verified two major advantages of the new balloon base: the ability to launch larger balloon system than at the SBC, and the ability to make the preparation process more efficient than at the SBC.

\subsection{The rest plans in FY2009}

The other five experiments scheduled in the mid-Augustto-mid-September season (B09-04 - 08) are being prepared at the each belonging institute. Those payloads will be moved to the TARF around one or two weeks prior to the each scheduled launch date.

The weight of these five payloads ranges from $100 \mathrm{~kg}$ to $600 \mathrm{~kg}$. The volume of the balloon ranges from $5,000 \mathrm{~m}^{3}$ to $300,000 \mathrm{~m}^{3}$. The expected observation hour at the level altitudes ranges from less than one hour to around 6 hours. Through the various balloon missions in FY2009, we intend to reflect credit on the new balloon base at the TARF.

\section{Summary}

The new Japanese balloon base at the TARF in Taiki, Hokkaido became operational in May 2008. In the summer of 2008, two engineering flights were carried out successfully resulting in verification of the establishment of the balloon base operation system.

In May/June 2009, the flight operations of the first three science experiments were performed successfully. Five more science flights are planned during August/September 2009. These flights will further establish the advantages of the new balloon base.

\section{Acknowledgments}

We would like to express our thanks to all involved in realising the transfer of the balloon base and starting the balloon operation at the TARF.

\section{References}

1) Fuke, H., Akita, D., Iijima, I. et al.: Developments of the Sliding Launcher and Related Facilities for the New Japanese Balloon Base, Trans. JSASS Space Tech. Jpn., 7 ists26 (2009), pp. Tm_7-Tm_11; ISTS 2008 (Hamamatsu), 2008-m-19p.

2) Hashimoto, T., Sawai S., Sakai S., et al.: Progress of Balloon-based Micro-gravity Experiment System, ISTS 2008 (Hamamatsu), 2008-h-22.

3) Kishimoto, Y., Gunji, S., Ishikawa, Y., et al.: Observation of Polarization for the Crab Nebula with PHENEX Polarimeter, ISTS 2009 (Tsukuba), 2009-m-28.

4) Shoji, Y., Onishi, T., Battazzo, S., et al.: Highly Precise Pointing Control System on a Balloon-Borne Telescope for Optical Observations of Planets, ISTS 2009 (Tsukuba), 2009-m-20.

5) Kimura, Y., Yamada, K., Akita, D., et al.: Study on Low-ballistic-coefficient Atmospheric-entry Technology using Flexible Aeroshell, ISTS 2008 (Hamamatsu), 2008-g-18.

6) Toyoda, S., Yoshida, N., Sugawara, S., et al.: Measurements of the Vertical Distributions of $\mathrm{N}_{2} \mathrm{O}$ Isotopomer Ratios in the Stratosphere Using a Balloon-Borne Cryogenic Sampler, ISTS 2008 (Hamamatsu), 2008-m-17p.

7) Shirasawa, Y., Mori, O., Sawada, H., et al: Demonstration of Solar Sail Deployment System Using a High Altitude Balloon, ISTS 2009 (Tsukuba), 2009-d-36.

8) Yamada, K., Izutsu, N., Fuke, H., et al.: Development of a superpressure balloon for practical missions, ISTS 2006 (Kanazawa), 2006-m-15p.

9) Tamura, T., Torii, S., Kasahara, K., et al.: CALET mission for the observation of cosmic rays on the International Space Station, ISTS 2008 (Hamamatsu), 2008-h-11.

10) Shimizu, Y., Torii, S., Kasahara, K., et al.: Balloon borne experiment with CALET prototype, ISTS 2008 (Hamamatsu), 2008-m-02.

11) Namiki, M., Matsuzaka, Y., Honda, H., et al.: Low Altitude Space Communication System, Adv. Space Res., 26 (2000), pp. 1431-1434.

12) Nishimura, J. and Hirosawa, H.: Systems for Long Duration Flights, Adv. Space Res., 1 (1981), pp. 239-249. 